\title{
Sex Differences in Self-Construal and in Depressive Symptoms: Predictors of Cross-National Variation
}

Journal of Cross-Cultural Psychology (C) The Author(s) 2020 (c) (1)

Article reuse guidelines: sagepub.com/journals-permissions DOI: I0.1 I 177/0022022I 20939655 journals.sagepub.com/home/jcc

@SAGE

Peter B. Smith' (D), Matthew J. Easterbrook', Heyla al-Selim², Vivian Miu Chi Lun ${ }^{3}$, Yasin Koc ${ }^{4}$, Pelin Gul', Dona Papastylianou ${ }^{6}$, Lusine Grigoryan ${ }^{7}$, Claudio Torres ${ }^{8}$, Maria Efremova ${ }^{9}$, Bushra Hassan ${ }^{10}$, Abd Halim Ahmad '", Ahmed al-Bayati' ${ }^{12}$, Joel Anderson 13, Susan E. Cross ${ }^{5}$, Gisela Isabel Delfino ${ }^{14}$, Vladimer Gamsakhurdia ${ }^{15}$ (D) Alin Gavreliuc ${ }^{16}$ (D), Dana Gavreliuc ${ }^{16}$, Ceren Gunsoy ${ }^{17}$ (i), Anna Hakobjanyan ${ }^{18}$, Siugmin Lay ${ }^{19}$, Olga Lopukhova ${ }^{20}$, Ping $\mathbf{H u}^{21}$, Diane Sunar ${ }^{22}$, Maria Luisa Mendes Texeira ${ }^{23}$, Doriana Tripodi ${ }^{24}$, Paola Eunice Diaz Rivera ${ }^{25}$, Yvette van Osch ${ }^{26}$, Masaki Yuki ${ }^{27}$, Ammar Abbas ${ }^{28}$, Natsuki Ogusu ${ }^{27}$, Catherine T. Kwantes ${ }^{29}$, Rolando Diaz-Loving ${ }^{25}$, Lorena Perez Floriano ${ }^{30}$, Trawin Chaleeraktrakoon ${ }^{31}(\mathbb{D}$, and Phatthanakit Chobthamkit ${ }^{32}$

\footnotetext{
'University of Sussex, UK

${ }^{2}$ King Saud University, Saudi Arabia

${ }^{3}$ Lingnan University, Hong Kong

${ }^{4}$ Groningen University, Netherlands

${ }^{5}$ lowa State University, USA

${ }^{6}$ University of Athens, Greece

${ }^{7}$ Ruhr University, Germany

${ }^{8}$ University of Brasilia, Brazil

${ }^{9} \mathrm{HSE}$ University, Russia

${ }^{10}$ International Islamic University, Pakistan

"Universiti Utara Malaysia, Malaysia

${ }^{12}$ Lawrence Technological University, USA

${ }^{13}$ Australian Catholic University and La Trobe University, Australia

${ }^{14}$ Pontifical Catholic University of Argentina, Argentina

${ }^{15}$ Ivane Javakhishvili Tbilisi State University, Georgia

${ }^{16}$ West University of Timisoara, Romania

${ }^{17}$ Clemson University, USA

${ }^{18}$ Yerevan State University, Armenia

${ }^{19}$ Pontificia Universidad Católica de Chile, Chile

${ }^{20}$ Kazan Federal University, Kazan, Russia

${ }^{21}$ Renmin University, China

${ }^{22}$ Istanbul Bilgi University, Turkey

${ }^{23}$ Mackenzie University, Brazil

${ }^{24}$ Gioia Tauro, Italy

${ }^{25}$ Autonomous University of Mexico, Mexico City
} 


\begin{abstract}
Sex differences in aspects of independent versus interdependent self-construal and depressive symptoms were surveyed among 5,320 students from 24 nations. Men were found to perceive themselves as more self-contained whereas women perceived themselves as more connected to others. No significant sex differences were found on two further dimensions of self-construal, or on a measure of depressive symptoms. Multilevel modeling was used to test the ability of a series of predictors derived from a social identity perspective and from evolutionary theory to moderate sex differences. Contrary to most prior studies of personality, sex differences in selfconstrual were larger in samples from nations scoring lower on the Gender Gap Index, and the Human Development Index. Sex differences were also greater in nations with higher pathogen prevalence, higher self-reported religiosity, and in nations with high reported avoidance of settings with strong norms. The findings are discussed in terms of the interrelatedness of selfconstruals and the cultural contexts in which they are elicited and the distinctiveness of student samples.
\end{abstract}

\title{
Keywords
}

self-construal, gender differences, gender equality, religiosity, independence versus interdependence

It is well established that on average men and women differ from one another in their self-perceptions, their values and their personality, as well as in the stereotypes that they hold about typical persons of a given sex (Eagly, 1987; McCrae et al., 2005; Schwartz \& Rubel, 2005; Williams $\&$ Best, 1990). Men typically see themselves as more agentic and women typically see themselves as more communal. The particular concern of this paper is with the ways in which these effects differ between cultural groups, as exemplified by variations in self-construal and in depressive symptoms. It was established some time ago that, across the 30 nations sampled by Williams and Best (1990), self-descriptions and gender stereotypes were more divergent in Western samples than in non-Western samples. The gap between stereotypes for men and for women was greater in nations identified by Hofstede (2001) as high on individualism and low on power distance. Similar sex differences have been found more recently for Big Five personality traits across 26 nations (Costa et al., 2001), across 56 nations (Schmitt et al., 2008), and across 53 nations (Lippa, 2010). Women have been found to score significantly higher than men on neuroticism, extraversion, agreeableness and conscientiousness. An index summarizing these differences at the national level showed significantly larger differences in nations scoring high on measures of gender empowerment, even after controlling for scores on the human development index (http://hdr.undp.org/statistics/data/indicators.cfm) (Schmitt et al., 2008). Similar effects have been reported more recently among adults from 20 nations (Mac Giolla \& Kajonius, 2018).

\footnotetext{
${ }^{26}$ Tilburg University, Netherlands

${ }^{27}$ Hokkaido University, Japan

${ }^{28}$ University of Baghdad, Iraq

${ }^{29}$ University of Windsor, Canada

${ }^{30}$ Diego Portales University, Chile

${ }^{31}$ Thammasat University, Thailand

${ }^{32}$ University of Kent, UK
}

\section{Corresponding Author:}

Peter B. Smith, School of Psychology, University of Sussex, Falmer, Brighton, BNI 9QH, UK.

Email: psmith@sussex.ac.uk 
However, among adults across 53 nations sex differences in Big Five personality were unrelated to gender equity for four of five dimensions (Lippa, 2010).

In this study we explore the related issue of sex differences in self-construal. Researchers into personality and self-construal both typically focus on variations in how respondents describe themselves on rating scales. However, the items on these scales differ in ways that reflect the contrasting assumptions of researchers in each field. While personality researchers acknowledge that behaviors vary across contexts (Mischel, 1977), they seek to identify the biologically rooted dispositions that underlie these variations. Big Five personality items typically describe a specific behavior or sentiment and rarely refer to context (McCrae \& Costa, 1997). In contrast, self-construal researchers have typically been concerned with how respondents report their relations with those around them (Markus \& Kitayama, 1991). Scale items tap the degree of respondents' investment in those around them and how this is sustained (Singelis, 1994). Self-construal theorists assign major potency to social context, showing that differing self-construals may be elicited by experimental manipulation or by daily involvement in settings with differing demand characteristics (Hong et al., 2000). Nonetheless, they observe that national differences in self-construal are found to be relatively consistent, most probably because the types of events that elicit a given type of self-construal occur more frequently in some cultures than in others (Smith et al., 2013).

Sex differences in self-construal have rarely been investigated cross-culturally, and we know little about the extent of such differences or whether they may be explained in a similar manner to sex differences in personality. In an early study, Kashima et al., (1995) proposed that while samples from different nations can be characterized in terms of varying endorsement of personal agency, differences between the sexes are more strongly related to variations in emotional relatedness to one another. This prediction was based on the premise that cultures have evolved in relation to the distinctive ecological challenges with which they must contend (Berry, 2018), whereas sex roles have traditionally derived from a division of labor between sustenance and child-rearing. Sampling students from two individualistic cultural groups (Australia and mainland USA) and three collectivistic cultural groups (Japan, Korea, and Hawaii), Kashima et al. (1995) found support for these hypotheses. The measure of agency (i.e., the extent to which people regard themselves as having independence of action and opinion) differentiated cultures but not sexes, whereas the measure of relatedness (i.e., the extent to which people regard themselves as emotionally related to others) differentiated both cultures and sexes. Put differently, sex differences were found in relation to some aspects of self-construal but not in relation to other aspects.

In this study, we first extend the work of Kashima et al. (1995) by investigating whether measures of self-construal show sex differences, using an improved measure of self-construal and a much broader range of samples. We also draw on the theoretical perspectives that have been advanced to account for the finding of a greater magnitude of sex differences in personality in Western nations. Given the contemporary emphasis upon gender equality, particularly within Western nations, these results have challenged theorists and researchers as to how best to explain them. Two principal explanations have been advanced, the first deriving from the application of social identity theory to the study of cultural differences (Guimond et al., 2007) and the second deriving from evolutionary theory (Schmitt, 2014; Schwartz \& Rubel-Lifschitz, 2009). We consider these two perspectives in turn, and then test hypotheses derived from them in relation to the perspective of Kashima et al. as predictors of sex differences in self-construal. In order to relate our design to prior studies sampling Big Five personality dimensions (Costa \& McCrae, 1995), we also test our predictions in relation to sex differences in depressive symptoms, which we include as a proxy for the personality dimension of neuroticism. 


\section{The Social Identity Perspective}

The most extensively investigated aspect of cross-cultural differences in self-construal has concerned variations in individualism-collectivism (Hofstede, 2001; Markus \& Kitayama, 1991). Persons within more individualistic cultures are typically found to describe themselves in ways that emphasize their independence of others, while those from more collectivistic cultures emphasize their relatedness to others. There has been extensive debate as to how to measure this contrast validly (Oyserman et al., 2002; Schimmack, Oishi \& Diener, 2005; Vignoles et al., 2016).

Guimond et al. (2006a) drew on the formulation of social identity known as self-categorisation theory (Turner et al., 1987) to predict the consequences of asking respondents to undertake different types of social comparison. In particular they contrasted comparing oneself with others of one's own sex, with the other sex, or a control condition where no explicit comparison was requested. Among samples of students from France and UK, participants were randomly assigned to these three experimental conditions. They found that asking respondents to rate themelves in comparison with the opposite sex yielded larger sex differences in self-construal than in either the within-sex or the control conditions. In a further study, samples were included from five Western European nations, USA, and two nations that are more collectivistic (Tunisia and Malaysia). It was again found that sex differences were greater for those making cross-sex comparisons (Guimond et al., 2006b; Guimond et al., 2007).

Having established that cross-sex comparisons yield larger sex differences, Guimond et al. were then able to address the key aspect of their study, namely their prediction that members of collectivist cultures are less inclined to engage in cross-sex comparisons, because their position in an established hierachy of roles requires only that they compare themselves with occupants of roles that are similar to their own roles. In their most collectivistic sample (Malaysia) they did indeed find no differences between responses to the within-sex versus cross-sex social comparison experimental conditions. Costa et al. (2001) also speculated that lesser sex differences in personality among respondents from Asia and Africa than in Europe and the Americas is because the respondents from Africa and Asia define their personality in terms of role occupancy rather than individual attributes.

The social identity perspective thus predicts that sex differences will be found where social comparisons with the opposite sex or others more generally are more salient, but provides only limited evidence from five nations that this is more likely to occur in individualistic nations. More generally, this perspective entails an extension of Markus and Kitayama's (1991) distinction between independence and interdependence. One's identity and distinctiveness in a collectivist context will be dependent on group identity, with an internal focus on group norms and on minimising the discomfort of deviance from those norms (Becker et al., 2014; Yuki, 2003). One's identity and distinctiveness in a more individualistic context will depend on the achievement of positive social comparisons and the avoidance of contexts that impair one's personal identity.

\section{The Evolutionary Perspective}

Sex differences have been identified on a very broad range of physical, biological, and psychological indices (Archer, 2019; Schmitt 2014). On many of these indices sex differences are found to be larger within Western nations (Schmitt, 2014). Greater sex differences in Western nations are found not just on self-report and stereotype measures, but also on objective attributes such as height, body-mass index, obesity and blood pressure. In Schmitt's view, differences of this type could in principle be mediated by facultative reactivity to ecological circumstances, or moderated by sociocultural factors such as religion, or by variations in sex role socialization. However, given that sex differences are greater in nations that score higher on gender empowerment, 
Schmitt finds that it is not plausible that these differences are attributable to gender role socialization. Using data from a 58-nation sample referred to as the International Sexuality Description Project 2, 26 of 28 different criteria disconfirmed predictions based on gender role socialization. In other words, on all these criteria, sex differences were greater in nations that score higher on gender role empowerment. Schmitt also argues that the explanation advanced by Guimond et al. (2007) is not tenable, as greater sex differences are found on criteria (e.g., height) where social comparison does not provide a plausible explanation. However, the two perspectives are not mutually exclusive in respect of most of the criteria that have been addressed by sex difference researchers,

Schwartz and Rubel-Lifschitz (2009) reported data from students and teachers in 68 nations supportive of the hypothesis that enhanced gender equality enables biologically predisposed sex differences in values to be more fully expressed. Gender equality also predicted greater sex differences in six specific values across representative samples from 76 nations (Falk \& Hermle, 2018).

The evolutionary perspective is more fully developed in Schmitt's (2014) application of life history theory to the findings that he reports. This theory posits the existence of biologically predisposed sex differences whose expression can be enhanced or diminished through life history. Schmitt highlights two aspects of life history. First, ecological stress due to harsh environmental conditions (e.g., resource scarcity, instability, high rates of violence and mortality) can diminish the expression of sex differences, since in these circumstances there is a shared priority of addressing the salient sources of stress. Ecological stress is higher in the nations that score low on gender equality (Fincher \& Thornhill, 2012). Second, according to Schmitt, religiosity can diminish differences through the promulgation of behavioral norms that are equally applicable across sexes. In his view, the world's major religions do not promulgate gender differentiation and predominantly endorse rule adherence and prosocial behaviors. Evidence supportive of 8 of 12 predictions relating to ecological stress and seven of nine predictions relating to religiosity derived from the International Sexuality Description Project 2 were presented. These effects remained significant after controlling for differences in national wealth and the human development index.

The finding of greater sex differences in Western samples poses the question of whether men and women contribute equally to the magnitude of these differences. Borkenau et al. (2013) reexamined the Big Five perceived personality data obtained from 51 nations by McCrae et al. (2005). Within this sample, women were perceived in relatively similar ways in all samples, whereas men were perceived in more varied ways, especially in Western samples. However, this effect was not found for neuroticism. Schmitt et al. (2008) also found that male personality varied more than female personality across nations. Thus, a summary of Schmitt's perspective would be that in cultural groups where stress and religiosity are low, men's inherent characteristics become more fully expressed, thereby emphasizing sex differences.

Taken together, it is apparent that prior findings converge in suggesting that sex differences in personality (and perhaps in self-construals) are on average greater in certain cultural settings, while explanations for these findings diverge. Research focusing on culture, social identity, and self-categorization explains these differences in terms of individualism-collectivism, social comparison, group identity and conformity pressures. In contrast, the evolutionary perspective explains the differences on the basis of life history, ecological threat and religiosity. The current study aims to elucidate the basis for sex differences in self-construal by sampling a wide range of cultural samples and using measures that cover self-construal and a personality index in the same study.

\section{The Present Project}

In this study, we employ a fuller range of samples than those of Kashima et al. (1995) and Guimond et al. (2007), and we differ from Schmitt's (2014) studies by also including additional 
predictors that are derived directly from our samples rather than from secondary sources. For instance, Schmitt's (2014) measure of stress was the index of pathogen stress (Fincher \& Thornhill, 2012). Although this measure is found to be associated with in-group ties and religiosity, it provides no direct indication of the extent to which any specific samples do experience stress.

There is also ambiguity in the existing literature as to the consistency and specificity of the sex effects that have been studied. Significant effects have been summarized across a range of personality dimensions (Schmitt et al., 2008) and values (Falk \& Hermle, 2018), when some specific measures in these studies actually showed no effect. Schmitt et al. (2008) reported sex differences in Big Five conscientiousness, but Costa et al. (2001) found only differences in the dutifulness facet of conscientiousness, and no effects for the five other facets of conscientiousness. The Big Five measure used by Schmitt did not provide separate facet scores. Schwartz and RubelLifschitz (2009) found sex differences for some specific value types, but not for others. As noted earlier, Kashima, et al. (1995) also found support for their hypothesis that sex differences are found only in relation to certain specific measures of self-construal. We therefore include measures for differing facets of self-construal.

Self-construal. In relation to our dependent measure of self-construal, measurement has typically contrasted independence with interdependence (Singelis, 1994). These measures have proved unreliable, leading to the development of improved indices that distinguish a series of facets of independent and interdependent self-construal (Vignoles et al., 2016). These more specific subscales can provide an indication of whether sex differences are found equally for all aspects of self-construal. Vignoles et al. identified seven facets of independence-interdependence, but in the present study only three of these are addressed, because they proved to have adequate structure within the present samples, as presented later. These subscales are named as self-containment versus connection to others, self-expression versus harmony, and consistency versus variability. The items defining each of these scales are shown in Table 2. The first named pole of each subscale refers to an aspect of independent self-construal, and the second named pole refers to an aspect of interdependent self-construal.

Depressive symptoms. Cross-national sex differences in depressive symptoms have been surveyed among respondents to the 1990 wave of the World Values Survey (Hopcroft \& Bradley, 2007). Across almost all of the 29 nations included, women were more depressed than men, particularly in nations scoring higher in gender equity. However, in this study depressive symptoms were measured on the basis of a Yes/No response to a single item ("During the past week did you ever feel depressed or very unhappy?"). Relevant cross-national surveys using more recent data have been those that more directly addressed the Big Five personality dimension of neuroticism. The neuroticism measure employed by Lippa (2010) comprised ten items whose content is closely similar to those to Radloff's (1977) CES-D measure of depressive symptoms. Across 53 nations, sex differences in neuroticism were unrelated to gender equity, and mean neuroticism was highest in samples from less economically developed nations (Lippa, 2010). Across large samples from 22 nations, NEO measures of neuroticism were also not significantly predicted by gender equity (Mac Giolla \& Kajonius, 2018).

Each of these studies sampled adults and each confirmed a sex difference in depressive symptoms/ neuroticism, but this effect has not been consistently related to gender equity. It appears that the relation between gender equity and sex differences in NEO measures may be strongest on personality dimensions other than neuroticism, particularly extraversion and agreeableness. In a further analysis of their data, Hopcroft and McLaughlin (2012) found support for the hypothesis that child rearing is stressful in high gender equity nations but is a source of support in less economically developed nations. Thus the linkage between gender equity and depressive 
symptoms found in their sample of adults might not be found in student samples that would include fewer parents.

\section{Hypotheses}

The hypotheses are formulated in terms of the broad distinction between independent and interdependent self-construal, and are also tested in relation to each of the subscales of this overall dimension recently developed, namely self-containment versus connection to others, self-expression versus harmony and consistency versus variability. In order to establish the comparability of our findings with those obtained in earlier studies, we first test the nominal prediction that there will be gender differences between samples in self-construal and in depressive symptoms.

Hypothesis 1: Across samples, women will report (a) more interdependent self-construals, and (b) higher depressive symptoms.

In developing predictions as to ways in which this hypothesis might fail, we consider first the perspective of Kashima et al. (1995). The three subscales of self-construal derived from the work of Vignoles et al. (2016) that are used in this study were not formulated specifically in terms of Kashima et al.'s work. Thus we are able to test their predictive ability only in an exploratory manner. The scales tapping self-containment (vs. connection to others) and self-expression (vs. harmony with others) come closer to Kashima et al.'s finding that sex differences concern relatedness rather than agency. Consistency versus variability come closer to defining agency. Thus, we predict:

Hypothesis 2: Across samples, sex differences in self-construal will occur in self-containment and self-expression but not in consistency.

The propositions derived from prior studies of sex differences in personality differ in content, but the social identity perspective and the evolutionary perspective both predict greater sex differences in more individualistic contexts. Thus in testing predictions derived from these perspectives, we are testing alternative explanations rather than alternative effects. We focus first upon the social identity perspective. We cannot test specific hypotheses that derive directly from differences in social comparison processes, as these were not measured. However, we take the related position that one's identities are a function of relevant norms. Although the salience of social norms has been shown to be particularly strong in collectivist groups (e.g., R. Bond \& Smith, 1996), norms for individualism can also provide strong behavioral guidance (Beauvois \& Dubois, 1988; Jetten et al., 2002; Lorenzi-Cioldi \& Chatard, 2006). Members of collectivist groups are strongly identified with their membership groups and are unlikely to anticipate any change in their membership of these groups (Markus \& Kitayama, 1991). The social norms of these groups will specify the ways in which one is expected to behave. Members will therefore be likely to feel discomfort if their behavior differs from what they perceive to be expected for those who are similar to oneself.

In contrast, within individualistic cultures, one's reputation and distinctiveness will depend on the evaluations of a broader range of those with whom one interacts. Social comparison will be less focused on behaving in ways that are similar to specific others and more concerned with actions that preserve one's individual distinctiveness (Markus \& Kitayama, 1991). By belonging to many groups, individuals can restrict the degree to which they are beholden to the norms of any one group (Prentice, 2006). This could include exercising one's choice to avoid spending time in groups that require one to behave in ways that do not accord with one's preferred identities. Within a given group, one's identity would be more reliant on achieving a role that is distinct 
from others of either gender, rather than on similarity with others (Jetten et al., 2002). The social identity perspective thus implies that sex differences should be greater where social expectations are individualistic rather than collectivistic.

Hypothesis 3: Women will be more interdependent than men in samples that are (a) lower in discomfort from social expectations; (b) higher in avoidance of settings with strong norms.

Finally, predictions in terms of the evolutionary perspective can be tested on the basis of Schmitt's (2014) findings that higher stress and lower religiosity in gender-empowered nations predict larger gender differences, whereas GDP and the human development index do not. The gender empowerment index employed by Schmitt has now been superseded by the Global Gender Gap Index (World Economic Forum, 2018), but within the present sample these indices correlate at 0.96 . The level of pathogen stress in societies as a whole used by Schmitt provides a distal predictor of stress. Hopcroft and Bradley (2007) have shown that across 24 nations, general population sex differences in depressive symptoms are larger in nations with higher gender equity. Schmitt et al. (2008) did not provide detail of their measure of religiosity. Self-identified religious affiliation provides a proximal measure.

Hypothesis 4: Women will be more interdependent than men in samples that score (a) nearer to gender equality on the Global Gender Gap Index; (b) lower in religiosity; (c) lower in stress.

\section{Method}

\section{Participants}

Participants were 5,230 students from 24 nations who completed the survey either online, in the classroom, or, in the Mexico City sample, by response to a request in public spaces. In some locations they received course credit, while in others they were thanked for their participation. Ethical consent for the research project was obtained from each university that was sampled. The data were collected in 2018. Respondents provided details of their age, gender, country of birth, nationality, ethnicity, and religion. The survey was originally constructed in English and was then translated into the language for use at each location, with subsequent back-translation and corrections based on discussion (van de Vijver \& Leung, 1997). Respondents who were not nationals of the location sampled were excluded from the data analysis. Details of the samples are provided in Table 1.

\section{Measures}

Self-construal. Vignoles et al. (2016) identified seven facets of independence-interdependence, with each facet tapped by six items. Each scale comprised some items phrased in terms of one pole of the dimension and other items phrased in terms of the alternate pole, in order to discount variations in acquiescent responding that are known to differ among cultural groups (Smith, 2004). Participants were asked, "How well does each of these statements describe you?" Ninepoint response scales were used, ranging from 1 (not at all) to 9 (exactly), with three intermediate anchor-points $(3=$ a little, $5=$ moderately, $7=$ very well $)$. Items were worded using "you," in order to make the task feel easier. The subscales measured: self-containment versus connection to others, self-direction versus openness to influence, self-expression versus harmony, consistency across situations versus variability, difference from others versus similarity with others, self-reliance versus dependence on others, and self-orientation versus commitment to others. 
Table I. Sample Details.

\begin{tabular}{lrccll}
\hline & $N$ & Mean age & Male & \multicolumn{1}{c}{ Language } & Data collection \\
\hline Argentina & 288 & 20.5 & 47 & Spanish & Online \\
Armenia & 128 & 20.2 & 24 & Armenian & Online \& Paper \\
Australia & 99 & 24.3 & 13 & English & Online \\
Brazil & 767 & 23.9 & 70 & Portuguese & Online \& Paper \\
Canada & 106 & 22.1 & 15 & English & Online \\
Chile & 106 & 20.1 & 32 & Spanish & Online \\
China - Beijing & 180 & 19.5 & 29 & Chinese & Online \\
Georgia & 101 & 21.0 & 31 & Georgian & Online \\
Greece & 304 & 21.7 & 19 & Greek & Online \& Paper \\
Hong Kong & 164 & 20.8 & 28 & Chinese & Online \\
Iraq & 85 & 22.2 & 52 & Arabic & Paper \\
Italy & 98 & 20.1 & 40 & Italian & Online \\
Japan & 105 & 20.2 & 51 & Japanese & Paper \\
Malaysia & 132 & 22.5 & 51 & Bahasa Malaya & Paper \\
Mexico & 223 & 21.6 & 55 & Spanish & Paper \\
Netherlands & 164 & 19.3 & 12 & Dutch & Online \\
Pakistan & 242 & 22.2 & 49 & Urdu & Paper \\
Romania & 261 & 22.3 & 47 & Romanian & Online \\
Russia & 647 & 21.2 & 44 & Russian & Online \& Paper \\
Saudi Arabia & 204 & 21.2 & 42 & Arabic & Paper \\
Thailand & 305 & 19.2 & 20 & Thai & Online \\
Turkey & 96 & 21.4 & 33 & Turkish & Online \\
UK & 132 & 19.8 & 10 & English & Online \\
USA - lowa & 287 & 18.9 & 36 & English & Online \\
\hline
\end{tabular}

Note. Male $=$ Percent Male.

To establish the structure of our self-construal items across samples, we followed a double standardization procedure similar to that used by Kashima et al. (1995). In order to discount individual differences in response style, we first made a within-subject standardization. Each item keyed toward independence was divided by the respondent's mean for all independence items. Each item keyed toward interdependence was divided by the respondent's mean of all interdependence items. In order to make data from different samples comparable with one another, we then standardized scores across samples.

An initial pan-cultural factor analysis using an oblimin rotation and including all of the 42 self-construal items drawn from the results of Vignoles et al. (2016) did not yield a structure that adequately represented all seven facets of self-construal. A subsequent analysis based on the items from Vignoles et al.'s measure that refer to three of these scales yielded the solution shown in Table 2. In order to determine the adequacy of the scales within each of the sampled nations, congruence coefficients were computed. As samples from some nations were small, data from nations that were judged culturally similar or geographically adjacent were grouped together, yielding ten clusters. ${ }^{1}$ The items defining the factor structure obtained within each of the clusters were compared in turn with the structure shown in Table 2 . All coefficients for factors exceeded 0.90 and 27/30 exceeded 0.95 . One hundred fifty-seven of 160 values for item congruence were at or above 0.90 , with 146 above 0.95 . Thus there is a satisfactory structure for the subscales employed in the present analysis. Variance explained was 40.9 percent. For clarity in subsequent discussion, signs for the loadings on the first two factors given in the table have been reversed, 
Table 2. Factor Analysis of Self-Construal Items.

\begin{tabular}{|c|c|c|c|}
\hline & 1 & 2 & 3 \\
\hline \multicolumn{4}{|l|}{ Self-containment versus connection to others } \\
\hline $\begin{array}{l}\text { If someone in your family achieves something, you feel proud as if you } \\
\text { had achieved something yourself }\end{array}$ & -0.14 & -0.62 & 0.06 \\
\hline $\begin{array}{l}\text { You would not feel personally insulted if someone insulted a member } \\
\text { of your family }\end{array}$ & -0.03 & 0.47 & -0.04 \\
\hline $\begin{array}{l}\text { If someone insults a member of your family, you feel as if you have } \\
\text { been insulted personally }\end{array}$ & -0.03 & -0.66 & -0.03 \\
\hline $\begin{array}{l}\text { If a close friend or family member is sad, you feel the sadness as if it } \\
\text { were your own }\end{array}$ & -0.05 & -0.64 & 0.04 \\
\hline $\begin{array}{l}\text { You usually do what people expect of you, rather than decide for } \\
\text { yourself what to do }\end{array}$ & -0.15 & 0.67 & 0.12 \\
\hline $\begin{array}{l}\text { If a close friend or family member is happy, you feel the happiness as if } \\
\text { it were your own }\end{array}$ & -0.06 & -0.75 & 0.03 \\
\hline \multicolumn{4}{|l|}{ Expressiveness versus Harmony } \\
\hline $\begin{array}{l}\text { You show your true feelings even if it disturbs the harmony in your } \\
\text { family relationships }\end{array}$ & 0.02 & .07 & .63 \\
\hline $\begin{array}{l}\text { You prefer to preserve harmony in your relationships, even if this } \\
\text { means not expressing your true feelings }\end{array}$ & -0.02 & -0.00 & -0.70 \\
\hline $\begin{array}{l}\text { You try to adapt to people around you, even if it means hiding your } \\
\text { feelings }\end{array}$ & 0.08 & 0.15 & -0.55 \\
\hline $\begin{array}{l}\text { You prefer to express your thoughts and feelings openly, even if it } \\
\text { may sometimes cause conflict }\end{array}$ & 0.07 & -0.00 & 0.68 \\
\hline \multicolumn{4}{|l|}{ Consistency versus Variability } \\
\hline You see yourself the same way even in different social environments & 0.51 & 0.01 & 0.01 \\
\hline You behave in a similar way at home and in public & 0.73 & -0.07 & 0.03 \\
\hline You act very differently at home compared to how you act in public & -0.69 & -0.13 & -0.03 \\
\hline You behave in the same way even when you are with different people & 0.72 & -0.11 & -0.02 \\
\hline You behave differently when you are with different people & -0.77 & -0.07 & -0.01 \\
\hline You see yourself differently when you are with different people & -0.67 & -0.01 & 0.02 \\
\hline
\end{tabular}

so that all scores refer to aspects of independence rather than of interdependence. This also permits computation of an overall mean score for independent self-construal, in addition to the three constituent facets.

Response to social expectations. The measures of response to perceived expectations were derived from nine items devised for this project. Respondents were asked to think of times when they had been in a situation in which certain behaviors were appropriate or expected, and how they reacted to such circumstances. Six items ("Discomfort") refer to discomfort in relation to perceived social expectations (example item: "In some situations, you are expected to behave in ways that would make you feel uncomfortable"). Three items ("Avoidance") refer to avoidance of perceived social expectations ("You usually avoid situations in which it is appropriate to behave in ways that would make you feel awkward"). Response scales for these items were the same as those used for the self-construal items. We sought to confirm the intended factor structure of this scale by running a multilevel confirmatory factor analysis on our data, using MPlus Version 8 (Muthén \& Muthén, 1998-2017). We specified two covarying factors at both levels (participants and nations), one representing a factor indicated by the six items referring to discomfort, and one indicated by the three items referring to avoidance. All the items were highly significant indicators of their respective factors $(p s<.001)$, and the model was an acceptable 
fit to the data $\left(\mathrm{CFI}=0.93, \mathrm{RMSEA}=0.08, \mathrm{SRMR}_{\text {within }}=0.046, \mathrm{SRMR}_{\text {between }}=0.15\right){ }^{2} \mathrm{We}$ therefore used these two factors as predictors in our models.

Religiosity. Respondents were asked to state their religious affiliation. Any identified affiliation was coded as 1. "None," "atheist" or "agnostic" were coded as $0 .{ }^{3}$

Depressive symptoms. Depression was measured with the 20-item version of the Centre for Epidemiological Studies Depression scale (CES-D) (Radloff, 1977). These items have 4-point response scales keyed in terms of frequency of symptom occurrence. A sample item is: "I felt that everything that I did was an effort." Four of the items describe positive symptoms and these are reverse keyed. Prior studies have indicated two factor solutions for the CES-D items, with the reverse keyed items defining the second factor (Carleton et al., 2013). We sought a solution in which the factor structure is not dependent on item reversal. The scores for the four reverse keyed items were therefore recoded, so that high scores reflect higher depression for all items. To overcome the disparity between item numbers and sample size, the 20 items were then summarized as five parcels, each defined by four items. Confirmatory factor analysis using MPlus 8 yielded a satisfactory one factor solution $(\mathrm{CFI}=0.998, \mathrm{RMSEA}=0.023, \mathrm{SRMR}=0.007)$.

Secondary predictors. Although this study focuses primarily upon indices provided by respondents, secondary measures are included in the analyses. The Global Gender Gap Index is published annually by the World Economic Forum (2018). It currently summarizes data for 149 nations on their progress towards gender parity on a scale from 0 (disparity) to 1 (parity) across four dimensions: the sub-indices for Economic Participation and Opportunity, Educational Attainment, Health and Survival, and Political Empowerment. Scores for 2018 for Gross Domestic Product adjusted for purchasing power parity were downloaded from the website of the International Monetary Fund, while the Human Development Index (2019) was downloaded from http:/hdr.undp.org/en/2019-report. Nation-level scores for pathogen stress were taken from Fincher and Thornhill (2008).

\section{Results}

Nation-level means for sex differences in self-construal and depressive symptoms are shown in Table 3. The averaged sex difference amounts to around a quarter of a standard deviation for selfcontainment and for expressiveness and much less for consistency and for the overall measure of independence and for depressive symptoms. Following Borkenau et al. (2013), variance ratios for each nation were computed by dividing the intrasex variance between males by the intrasex variance between females. The mean variance ratio for independence/ interdependence was 1.02, providing no evidence that male variance in self-construal is greater than female variance. The mean variance for depressive symptoms was 1.03 , giving no evidence that men varied more than women in depressive symptoms. However, variance ratios for depressive symptoms varied substantially between nations, ranging from 1.43 to 0.71 .

Table 4 provides tests of hypotheses 1 and 2. Hierarchical linear modeling using Mplus8 showed that when the three self-construal subscales are regressed on sex, self-containment versus connection to others is significantly higher among men. There is also a trend for expressiveness versus harmony to be significantly higher among women. However, no sex differences are found for self-consistency versus variability or for depressive symptoms. Furthermore, the random slope indices indicate that none of the relationships between these measures and sex shows significant variation between samples. Hypothesis 1 is thus supported by the effect for self-containment versus connection to others, and by the lack of effect for consistency versus variability, as specified in Hypothesis 2. 
Table 3. Nation-level Means for Self-Construal and Depressive Symptoms by Sex.

\begin{tabular}{|c|c|c|c|c|c|c|c|c|c|c|}
\hline & \multicolumn{2}{|c|}{ INT } & \multicolumn{2}{|c|}{ CONT } & \multicolumn{2}{|c|}{ EXPR } & \multicolumn{2}{|c|}{ CONS } & \multicolumn{2}{|c|}{ CESD } \\
\hline & $M$ & $F$ & $M$ & $F$ & $M$ & $F$ & $M$ & $F$ & M & $\mathrm{F}$ \\
\hline Argentina & 09 & 20 & 16 & -16 & -01 & 28 & 14 & 47 & 23 & 02 \\
\hline Armenia & -17 & -21 & -60 & -63 & 13 & 22 & -03 & -22 & -06 & -02 \\
\hline Australia & -11 & 13 & 01 & 29 & -06 & 17 & -28 & -06 & -14 & -04 \\
\hline Brazil & 20 & 13 & 17 & -14 & 02 & 08 & 41 & 47 & -02 & 02 \\
\hline Canada & 10 & 03 & 38 & 12 & 이 & 13 & -07 & -15 & II & 08 \\
\hline Chile & -18 & 00 & 31 & -27 & -59 & -04 & -28 & 31 & 05 & -08 \\
\hline China & -36 & -30 & 08 & 05 & -37 & -23 & -80 & -71 & -12 & -20 \\
\hline Georgia & -13 & -06 & -34 & -68 & 37 & 67 & -44 & -18 & -05 & -13 \\
\hline Greece & -30 & -16 & -49 & -63 & -07 & 35 & -34 & -20 & -13 & -19 \\
\hline Hong Kong & -16 & -05 & 42 & 40 & -38 & -19 & -53 & -36 & -01 & 01 \\
\hline Iraq & -13 & -18 & -17 & -48 & -28 & -33 & 06 & 26 & -04 & -13 \\
\hline Italy & 04 & -06 & -63 & -97 & 25 & 33 & 50 & 48 & 06 & -04 \\
\hline Japan & 00 & -04 & 55 & 33 & -36 & 03 & -21 & -47 & -03 & -15 \\
\hline Malaysia & 23 & 07 & 71 & 41 & 04 & -21 & -06 & 01 & -02 & 01 \\
\hline Mexico & 02 & -16 & -25 & -15 & 23 & -15 & 07 & -19 & -08 & -06 \\
\hline Netherlands & 21 & 18 & 46 & 37 & 34 & 02 & -17 & 15 & -08 & -05 \\
\hline Pakistan & 07 & -05 & 33 & & 12 & -16 & -08 & -14 & -19 & 08 \\
\hline Romania & -18 & -10 & -39 & -45 & -19 & 07 & 04 & 08 & 02 & 13 \\
\hline Russia & 10 & 01 & 33 & II & 01 & 07 & -03 & -14 & 00 & -01 \\
\hline Saudi Arabia & -28 & -42 & -34 & -87 & -31 & -21 & -19 & -19 & 04 & 10 \\
\hline Thailand & -06 & -20 & 56 & 21 & -48 & -54 & -25 & -26 & 00 & 07 \\
\hline Turkey & 05 & 11 & -24 & -68 & 18 & 66 & 21 & 35 & -04 & -06 \\
\hline UK & 06 & 15 & 85 & 31 & -63 & 06 & -04 & 08 & 05 & -03 \\
\hline USA & 17 & 14 & 36 & 31 & 01 & 04 & 12 & 07 & 05 & II \\
\hline Average & & & & & & & & & & \\
\hline Difference & \multicolumn{2}{|c|}{08} & \multicolumn{2}{|c|}{25} & \multicolumn{2}{|c|}{23} & \multicolumn{2}{|c|}{07} & \multicolumn{2}{|c|}{07} \\
\hline
\end{tabular}

Note. Means are Standard Scores $\times 100$. CONT $=$ Self-Containment versus Connection to Others; EXPR $=$ SelfExpression versus Harmony; CONS = Self-Consistency versus Variability; CESD = Depression.

Table 4. Hierarchical Linear Model Testing Association of Self-Construal Dimensions and Depressive Symptoms with Sex.

\begin{tabular}{lclll}
\hline Dependent variables & 1 & 2 & 1 & 2 \\
\hline Self-containment & $-0.050^{* * *}$ & $0.002^{* *}$ & & \\
Self-expressiveness & 0.015 & 0.000 & & \\
Self-consistency & -0.003 & 0.001 & & 0.000 \\
Depressive symptoms & & & $0.211^{* * *}$ & $0.211^{* * *}$ \\
Residual & $0.208^{* * *}$ & $0.207^{* * *}$ & & \\
Level-2 residual & $0.024^{* * *}$ & $0.023^{* * *}$ & & \\
Self-consistency RS & & 0.000 & & 0.002 \\
Self-expression RS & & 0.001 & & \\
Self-containment RS & & 0.000 & & \\
Depressive symptoms RS & & & & \\
\hline
\end{tabular}

Note. Female scores high; RS $=$ Random Slope.

$* p<.05 . * * p<.01$. ***p $<.001$. 
Table 5. Nation-level Means for Moderator Variables.

\begin{tabular}{lcccccrr}
\hline & GGI & PPP & HDI & RELIG & PATH & DISC & AVOID \\
\hline Argentina & 73 & 20537 & 83 & 80 & 37 & -0.63 & 0.08 \\
Armenia & 68 & 10176 & 76 & 90 & 28 & 0.17 & 0.28 \\
Australia & 73 & 52373 & 94 & 58 & 27 & 0.38 & -0.13 \\
Brazil & 68 & 16154 & 76 & 89 & 45 & -0.17 & -0.20 \\
Canada & 77 & 49651 & 93 & 62 & 26 & 0.24 & -0.08 \\
Chile & 72 & 25978 & 84 & 62 & 29 & -0.27 & 0.25 \\
China & 67 & 18110 & 75 & 18 & 37 & 0.75 & 0.61 \\
Georgia & 68 & 11485 & 78 & 92 & 28 & -0.07 & 0.05 \\
Greece & 70 & 29123 & 87 & 90 & 30 & -0.02 & 0.22 \\
Hong Kong & 67 & 64706 & 93 & 15 & 25 & 0.31 & 0.17 \\
Iraq & 55 & 17659 & 69 & 100 & 35 & -0.03 & -0.34 \\
Italy & 71 & 39637 & 88 & 91 & 26 & -0.93 & -0.08 \\
Japan & 66 & 44277 & 91 & 29 & 28 & -0.30 & -0.51 \\
Malaysia & 68 & 30860 & 80 & 100 & 36 & 0.28 & -0.24 \\
Mexico & 72 & 20602 & 77 & 78 & 37 & -0.71 & -0.09 \\
Netherlands & 75 & 56383 & 93 & 32 & 24 & -0.27 & -0.25 \\
Pakistan & 55 & 5680 & 56 & 100 & 35 & 0.13 & 0.18 \\
Romania & 71 & 26447 & 81 & 91 & 27 & -0.43 & 0.22 \\
Russia & 70 & 29267 & 82 & 91 & 28 & 0.35 & -0.02 \\
Saudi Arabia & 59 & 55944 & 85 & 100 & 37 & -0.34 & -0.46 \\
Thailand & 70 & 19476 & 76 & 92 & 41 & 0.44 & 0.14 \\
Turkey & 63 & 27956 & 79 & 65 & 39 & -0.49 & 0.18 \\
UK & 77 & 45705 & 92 & 34 & 26 & 0.47 & -0.11 \\
USA & 72 & 62606 & 93 & 85 & 29 & 0.50 & 0.06 \\
\hline Note. GG & & & & & & 29 & \\
\hline
\end{tabular}

Note. GGI = Global Gender Gap Index × 100; PPP = GDP adjusted for Purchasing Parity; HDI = Human Development Index; RELIG = Religiosity of present samples: In Iraq and Saudi Arabia, respondents were assumed all to be religious and the question was omitted; PATH = Pathogen Stress; DISC = Discomfort; AVOID = Avoidance.

Tables 5 and 6 shows means for the various moderators to be used in testing Hypotheses 3 and 4 , as well as correlations between them. There are substantial positive associations between the Global Gender Gap Index (GGI), GDP and the Human Development Index (HDI), and as would be expected, these indices tend toward negative associations with the scores for religiosity and pathogen stress.

Table 7 provides analyses using a composite measure of independence versus interdependence, combining the three self-construal subscales. While this measure shows no significant relation to sex it does have a strongly significant random slope, as detailed in Table 7. Since significant random slope is found only for this composite measure, it can be used to test Hypotheses 3 and 4. Table 7 shows a series of multilevel models testing explanations for variation in the relation of independence/interdependence to sex. The continuous predictors were grand mean centered. Models 1 and 2 indicate that there is a small tendency for women to score higher on independence in the overall sample, while the random slope index in Model 2 indicates that there is a significant degree of variation across samples. We tested our hypotheses in a series of models that included cross-level interactions. In all the models, there was no significant main effect for gender, although in every model the coefficient indicated that women tended to be slightly more interdependent than men.

We consider the five models where a significant cross-level interaction term is found. Model 3 segments the data in terms of national scores for GGI. The significant interaction term indicates 
Table 6. Correlations between Nation-level Moderators.

\begin{tabular}{lcccccrr}
\hline & GGI & PPP & HDI & RELIG & PATH & DISC & AVOID \\
\hline IND & $0.44^{*}$ & 0.24 & 0.31 & -0.10 & -0.12 & -0.06 & -0.29 \\
GGI & - & 0.34 & $0.69 * *$ & -0.33 & $-0.43^{*}$ & 0.05 & 0.11 \\
PPP & & - & $0.85^{* * *}$ & $-0.47^{*}$ & $-0.51^{*}$ & 0.12 & -0.38 \\
HDI & & & - & $-0.50^{*}$ & $-0.60^{* *}$ & 0.02 & -0.26 \\
RELIG & & & & - & 0.36 & -0.24 & -0.11 \\
PATH & & & & & - & -0.08 & 0.02 \\
DISC & & & & & & - & 0.28 \\
\hline
\end{tabular}

Note. IND = Mean Independence; GGI = Global Gender Gap Index; PPP = GDP adjusted for Purchasing Parity; $\mathrm{HDI}=$ Human Development Index; RELIG = Religiosity of present samples; PATH = Pathogen Stress; DISC = Discomfort; AVOID = Avoidance.

$*_{p}<.05 . * * p<.01$. ***p $<.001 . n=24$.

that women become significantly more interdependent than men in nations with low GGI scores and significantly more independent than men in nations with high GGI scores. Model 5 indicates a similar result for nations scoring lower on HDI. These results are contrary to Hypothesis 4a, which was derived from the evolutionary perspective. Consistent with these effects, Model 7 indicates that while there is no overall sex difference in relation to levels of pathogen stress, women are more interdependent than men in nations that are higher on pathogen stress. This is contrary to Hypothesis 4c, also based on the evolutionary perspective. Model 6 shows that women become more interdependent than men as the aggregate self-reported religiosity of the nation increases. This supports Hypothesis $4 \mathrm{~b}$. Finally, Model 9 indicates that while there is no sex difference in relation to levels of avoidance, women are more interdependent in samples where avoidance is high. This supports Hypothesis $3 \mathrm{~b}$, but there is no effect for the discomfort measure specified in Hypothesis 3a. The table indicates that the percentage of between-nation variance explained by these effects ranges from 4 to 30 .

\section{Discussion}

This study has provided evidence for the continuing presence of sex differences in self-construal across a broad range of samples drawn from different nations. Consistent with the results of Kashima et al. (1995), Costa et al. (2001) and Schmitt et al. (2008), differences were found on some subscales but not on others. Estimated differences on the self-construal subscales were between 0.07 and 0.25 of a standard deviation on the self-construal subscales, but only .07 for depressive symptoms. This compares with 0.15 for agreeableness, 0.12 for conscientiousness, 0.10 for extraversion, but 0.40 for neuroticism reported by Schmitt et al. (2008). However, the findings pose questions as to possible differences in the extent of sex differences in self-construal compared to those found in personality measures, whether differences vary between the populations sampled, and whether they may be explained in terms of the same predictors.

Firstly, the gender differences in self-construal that we obtained replicate those obtained in the prior study by Kashima et al. (1995). In relation to the study by Kashima et al., our sample was much more extensive, and the sampling was undertaken 20 years later. Both studies sampled students, as have most studies concerning gender differences in Big Five personality traits. Like Kashima et al., we found sex differences on the subscale most closely linked with relatedness, with women scoring higher than men on seeing themselves as more connected to others. Furthermore, as predicted, the more agentic orientation implied by self-consistency showed no sex difference, as Kashima et al. had earlier found. The subscale tapping expressiveness versus 


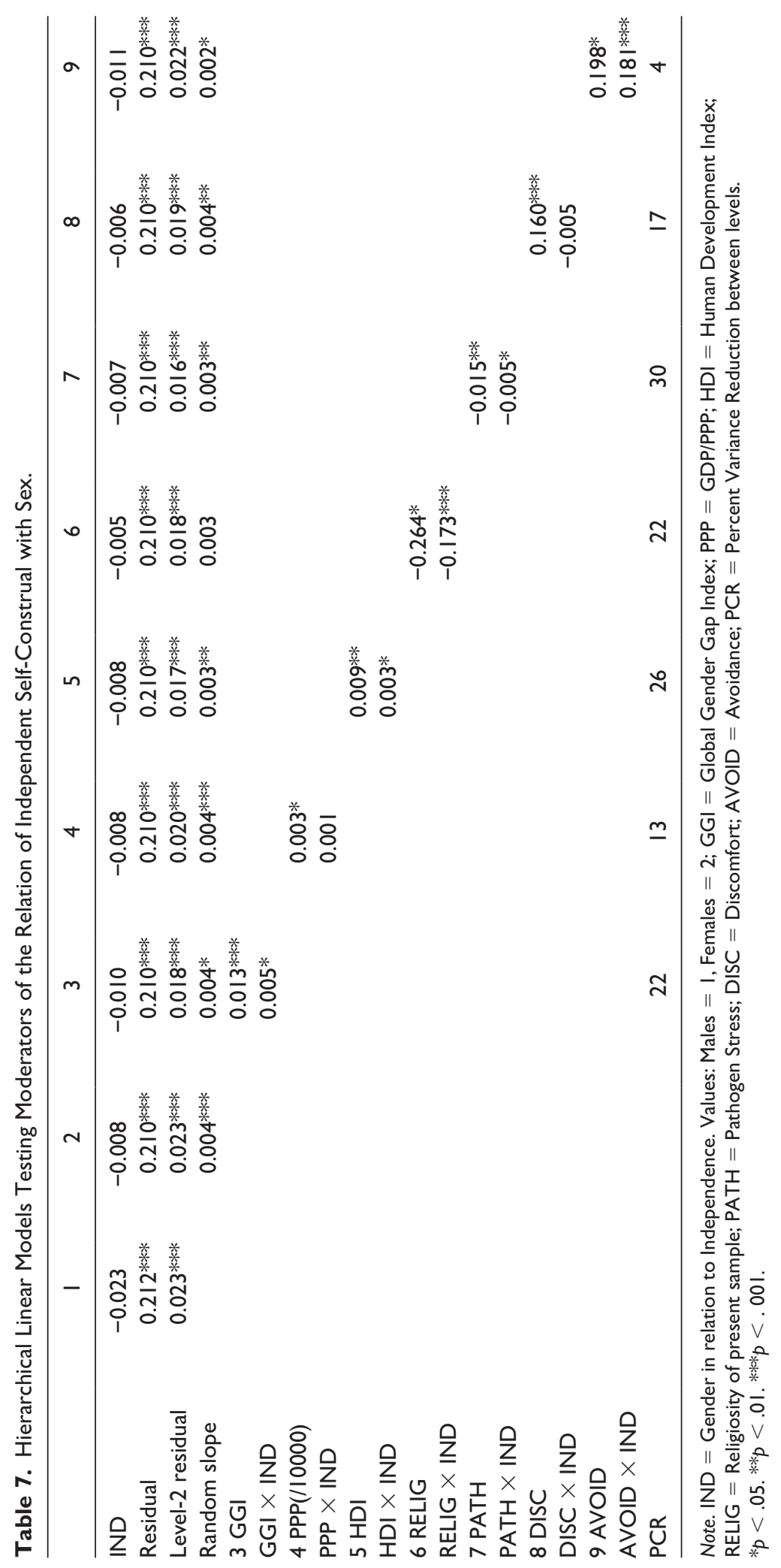


harmony also showed no difference, and it may be unsuited to tapping sex differences, as women are not only frequently more concerned with harmony but also often more expressive. Evidence for the validity of this subscale is that it does show the expected contrast between high harmony for Asian samples and high expressiveness elsewhere (Vignoles et al., 2016). Given the lack of effect for some subscales, we found that only the 17-item overall measure of independence versus interdependence yielded random slope indices. These provided the most defensible basis for testing explanations of the differences obtained.

Our larger sampling of cultural groups and the availability of additional measures enabled us to extend the analysis by Kashima et al. (1995) by testing alternative explanations for the sex effects that we obtained. Here we find that the basic proposition advanced by proponents of both the social identity and the evolutionary perspectives that sex differences will be greater in samples that are higher on the Global Gender Gap Index, on the Human Development Index and on pathogen stress is not supported by our data. We consider next whether these effects could best be understood in terms of conceptualization, measurement or sampling.

Conceptualization. The evolutionary account of increased sex differences in personality within nations high on gender equity rests upon evidence for the genetic determinants of personality. Self-construals are conceptualized as cultural adaptations to context, and may therefore be more labile and more responsive to a variety of local determinants, including inducements toward different types of social comparisons. More direct evidence will be required of the locally predominant focus of social comparisons in relation to respondent sex before one could know whether the present result is attributable to variations in who compares themselves to who.

If the contrast between the results for self-construal and those reported earlier for personality could be attributable to the differing ways in which these variables are conceptualized, the results obtained with the measure of depressive symptoms that was included as a proxy personality variable becomes relevant. However, we obtained findings consistent with those of Lippa (2010) that sex differences in neuroticism are unrelated to gender equity, as well as the findings of Borkenau et al. (2013) that men do not vary more than women in perceived neuroticism. Measures of the Big Five personality dimensions that do show sex differences would be required to further clarify the contrasting conceptualizations.

Measurement. The effects that were obtained for self-rated religiosity and avoidance of norms provide suggestions as to more fruitful lines of investigation. These variables are both proximal rather than distal in nature. Proximal predictors are more likely to capture the attributes characterizing student groups than predictors that summarize attributes of national groups as a whole. Schmitt (2014) proposed that high religiosity would attenuate gender differences and this effect was also found in the present data. As Table 5 indicates, reported religiosity was high in most samples. This effect may therefore be driven by the low sex differences found in those few samples with low reported religiosity: Japan, China, Hong Kong, UK, and the Netherlands.

The measures of discomfort in relation to social expectations and avoidance of normatively constrained settings were newly developed and further investigation will be required to determine their validity. Avoidance is likely to be more possible in groups whose norms are loose rather than tight (Gelfand et al., 2011). In the present data, avoidance of social expectations was particularly low in Saudi Arabia, Japan and Iraq. The finding of a significant moderation by this type of measure is consistent with the social identity perspective of Guimond et al. (2007).

Sampling. The predictions of sex differences in self-construal and depressive symptoms, and of the ways in which predictors may moderate their occurrence were only partially supported. Testing of these types of hypothesis requires a substantial number of samples, and coverage of only 
24 nations may have been insufficient to avert Type 1 errors. Nonetheless, distinctive effects were already obtained, albeit at modest levels of significance.

If context may be a stronger determinant of sex differences in self-construal than it is for sex differences in personality, it becomes important to consider the contexts that are sampled in particular studies. The research of Hopcroft and McLaughlin (2012) illustrates one of the factors that may affect sex differences in the general population much more than in student populations. These authors found that the larger sex difference in depressive symptoms in high gender equity nations (Hopcroft \& Bradley, 2007) could be explained by the greater stress of raising children in high gender-equity nations. While we found no overall sex difference in depressive symptoms, some samples showed much greater variability than others, suggesting that local factors may have affected the relation between sex and depressive symptoms.

Although all of the most relevant prior studies did also sample students, there is a substantial time gap between the collection of the present data in 2018 and the earlier data collection dates. The data analyzed by Schmitt et al. (2008) were collected in approximately 2001 to 2002, with that collected by Costa et al. (2001) and Kashima et al. (1995) being drawn from the preceding decade. The studies by Lippa (2010) and Mac Giolla and Kajonius (2018) sampled adults rather than students, with their data collected in 2005 and between 2006 and 2011 respectively. We have substantial evidence of recent cultural change in many nations from successive waves of the World Values Survey (Li \& Bond, 2010; Inglehart \& Oyserman, 2004; Welzel, 2013), focused particularly on increased individualism and endorsement of emancipative values. Student groups are likely to be in the forefront of such change. Furthermore, self-construals are likely to be more amenable to cultural change than personality traits. Recent cultural changes may certainly tend to reduce sex differences in self-construal, but our data find differences to be still present. It is equally possible that cultural changes such as secularization, expansion of higher education and students' reliance on social media will cause a convergence between cultures in the strength of the factors that enhance or diminish sex differences. We need to know more about the norms characterizing gender relations within current campus cultures and their possible implications for those types of sex difference that are less directly linked with biologically evolved differences.

\section{Conclusion}

This study has presented evidence for a somewhat different picture of sex differences in selfconstrual among contemporary student populations than might be predicted on the basis of prior studies of sex differences. Across samples we find no evidence for culture-general sex differences. Instead we find that women see themselves as more interdependent in contexts low in gender equity and more independent in contexts high on gender equity. We require further evidence as to the replicability of this finding and fuller testing of explanations that are specifically distinctive to determinants of self-construal.

\section{Declaration of Conflicting Interests}

The author(s) declared no potential conflicts of interest with respect to the research, authorship, and/or publication of this article.

\section{Funding}

The author(s) disclosed receipt of the following financial support for the research, authorship, and/or publication of this article: The work of Maria Efremova was supported by the framework of the HSE Basic Research Program. Aside from this, the authors received no financial support for the research, authorship and/or publication of this article. 


\section{ORCID iDs}

Peter B. Smith (iD https://orcid.org/0000-0002-5300-2611

Vladimer Gamsakhurdia (iD) https://orcid.org/0000-0002-5297-4777

Alin Gavreliuc (D) https://orcid.org/0000-0001-8411-0327

Ceren Gunsoy (iD https://orcid.org/0000-0001-9505-6178

Trawin Chaleeraktrakoon (iD) https://orcid.org/0000-0001-7164-9307

\section{Notes}

1. The clusters were Anglo, Brazil, Caucasus, East Asian, Latin American, North European, Mediterranean, Middle Eastern, Russian, Southeast Asian.

2. Here, we follow Rutkowski and Svetina (2014), who recommended that where the number of samples is large, ". . .SRMR is not used in isolation, if it is used at all. Rather, it should be used in conjunction with the CFI and TLI. And where inconsistencies in these measures arise, the analyst would be better served by relying on the CFI and TLI" (p.52).

3. Nation-level percentages for religiosity were also taken from the World Values Survey, waves 5 and 6. The two measures correlated at $0.78, n=23$, supporting the representativeness of our samples.

\section{References}

Archer, J. (2019). The reality and evolutionary significance of human psychological sex differences. Biological Reviews, 94(4), 1381-1415.

Beauvois, J. L., \& Dubois, N. (1988). The norm of internality in the explanation of psychological events. European Journal of Social Psychology, 18(4), 299-316.

Becker, M., Vignoles, V. L., Owe, E., Easterbrook, M. J., Brown, R., Smith, P. B., Bond, M. H., Regalia, C., Manzi, C., Brambilla, M., Aldhafri, S., González, R., Carrasco, D., Paz Cadena, M., Lay, S., Schweiger Gallo, I., Torres, A., Camino, L., Özgen, E., Güner, Ü. E., . . .Koller, S. H. (2014). Cultural bases for self-evaluation: Seeing oneself positively in different cultural contexts. Personality and Social Psychology Bulletin, 40, 657-675.

Berry, J. W. (2018). Ecocultural perspective on human behaviour. In A. Uskul \& S. Oishi (Eds.), Socioeconomic environment and human psychology (pp. 1-18). Oxford University Press.

Bond, R., \& Smith, P. B. (1996). Culture and conformity: A meta-analysis of studies using Asch's (1952b, 1956) line judgment task. Psychological Bulletin, 119(1), 111-137.

Borkenau, P., McCrae, R. R., \& Terracciano, A. (2013). Do men vary more than women in personality? A study in 51 cultures. Journal of Research in Personality, 47(2), 135-144.

Carleton, R. N., Thibodeau, M., Teale, M., Welch, P., Abrams, M., Robinson, T., \& Asmundson, G. (2013). The center for epidemiologic studies depression scale: A review with a theoretical and empirical examination of item content and factor structure. Plos One, 8(3): e58067. https://doi.org/10.1371/journal. pone. 0058067 .

Costa, P. T., \& McCrae, R. R. (1995). Domains and facets: Hierachical personality assessment using the revised NEO personality inventory. Journal of Personality Assessment, 64(1), 21-50.

Costa, P. T., Terracciano, A., \& McCrae, R. R. (2001). Gender differences in personality traits across cultures: Robust and surprising findings. Journal of Personality and Social Psychology, 81(2), 322-331. https://doi.org/10.1037/0022-3514.81.2.322

Eagly, A. (1987). Sex differences in social behavior. Erlbaum.

Falk, A., \& Hermle, J. (2018). Relationship of gender differences in preferences to economic development and gender equality. Science, 362(6412), eaas 9899 .

Fincher, C. L., \& Thornhill, R. (2008). Assortative sociality, limited dispersal, infectious disease and the genesis of the global pattern of religion diversity. Proceedings of the Royal Society B, 275(1651), $2587-2594$

Fincher, C. L., \& Thornhill, R. (2012). Parasite stress promotes in-group assortative sociality: The cases of strong family ties and heightened religiosity. Behavioral and Brain Sciences, 35(2), 61-79.

Gelfand, M. J., Raver, J. L., Nishii, L, Leslie, L., Lun, J., Lun, B. C., Duan, L., Almaliach, A., Ang, S., Arnadottir, J., Aycan, Z., Boehnke, K., Boski, P., Cabecinhas, R., Chan, D., Chhokar, J., D’Amato, A., 
Ferrer, M., Fischlmayr, I. C., Fischer, R., . . Y Yamaguchi, S. (2011). Differences between tight and loose cultures: A 33 nation study. Science, 332(6033), 1100-1104.

Guimond, S., Branscombe, N., Brunot, S., Buunk, A. P., Chatard, A., Desert, M., Garcia, D. M., Haque, S., Martinot, D., \& Yzerbyt, V. (2007). Culture, gender and the self: Variations and impact of social comparison processes. Journal of Personality and Social Psychology, 92(6), 1118-1134.

Guimond, S., Chatard, A., Branscombe, N., Brunot, S., Buunk, A. P., Conway, M., Crisp, R. J., Dambrun, M., Désert, M., Garcia, D. M., Haque, S., Leyens, J.-P., Lorenzi-Cioldi, F., Martinot, D., Redersdorff, S., \& Yzerbyt, V. (2006a). Social comparison across cultures 11: Change and stability in self-views experimental evidence. In S. Guimond (Ed.), Social comparison and social psychology: Understanding cognition, intergroup relations and culture (pp. 318-344). Cambridge University Press.

Guimond, S., Chatard, A., Martinot, D., Crisp, R., \& Redersdorff, S. (2006b). Social comparison, selfstereotyping, and gender differences in self-construals. Journal of Personality and Social Psychology, 90(2), 221-242.

Hofstede, G. (2001). Culture's consequences: Comparing values, behaviors, institutions and organizations across nations. Sage.

Hong, Y. Y., Morris, M. W., Chiu, C. Y., \& Benet Martinez, V. (2000). Multicultural minds: A dynamic constructivist approach to culture and cognition. American Psychologist, 55(7), 709-720.

Hopcroft, R. L., \& Bradley, D. B. (2007). The sex difference in depression across 29 countries. Social Forces, 85(4), 1483-1507.

Hopcroft, R. L., \& McLaughlin, J. (2012). Why is the sex gap in feelings of depression wider in high gender equity countries? The effect of children on the psychological well-being of men and women. Social Science Research, 41(3), 501-513.

Inglehart, R., \& Oyserman, D. (2004). Individualism, autonomy and self-expression: The human development syndrome. In H. Vinken, J. Soeters, \& P. Ester (Eds.), Comparing cultures: Dimensions of culture in a comparative perspective (pp. 74-96). Brill.

Jetten, J., Postmes, T., \& McAuliffe, B. J. (2002). "We're all individuals": Group norms of individualism and collectivism, levels of identification and identity threat. European Journal of Social Psychology, 32(2), 189-207.

Kashima, Y., Yamaguchi, S., Kim, U., Choi, S.-C., Gelfand, M. J., \& Yuki, M. (1995). Culture, gender, and self: A perspective from individualism-collectivism research. Journal of Personality and Social Psychology, 69(5), 925-937.

Li, L. M. W., \& Bond, M. H. (2010). Value change: Analyzing national change in citizen secularism across four time periods in the World Values Survey. The Social Science Journal, 47, 294-306.

Lippa, R.A. (2010). Sex differences in personality traits and gender-related occupational preferences across 53 nations: Testing evolutionary and social-environmental theories. Archives of Sexual Behavior, 39(3), 619-636.

Lorenzi-Cioldi, F., \& Chatard, A. (2006). The cultural norm of individualism and group status: The implications for social comparison. In S. Guimond (Ed.), Social comparison and social psychology: Understanding cognition, intergroup relations and culture (pp. 264-282). Cambridge University Press.

Mac Giolla, E., \& Kajonius, P. (2018). Sex differences in personality are larger in gender equal countries: Replicating and extending a surprising finding. International Journal of Psychology, 54(6), 705-711. https://doi.org/10.1002/ijop.12529

Markus, H. R., \& Kitayama, S. (1991). Culture and the self: Implications for cognition, emotion, and motivation. Psychological Review, 98(2), 224-253.

McCrae, R. R., \& Costa, P. T., Jr. (1997). Personality trait structure as a hman universal. American Psychologist, 52, 509-516.

McCrae, R. R., \& Terracciano, A., \& Personality Profiles of Cultures Project. (2005). Universal features of personality traits from the observer's perspective: Data from 50 cultures. Journal of Personality and Social Psychology, 88(3), 547-561. https://doi.org/10.1037/0022-3514.88.3.547

Mischel, W. (1977). The interaction of person and situation. In E. Magnusson \& N. S. Endler (Eds.), Personality at the crossroads: Current issues in interactional psychology (pp. 333-352). Erlbaum.

Muthén, L. K., \& Muthén, B. O. (1998-2017). Mplus user's guide (6th ed.). Muthén \& Muthén.

Oyserman, D., Coon, H. M., \& Kemmelmeier, M. (2002). Rethinking individualism and collectivism: Evaluation of theoretical assumptions and meta-analyses. Psychological Bulletin, 128(1), 3-72 
Prentice, D. A. (2006). Acting like an individual versus feeling like an individual. In T. Postmes \& J. Jetten (Eds.), Individuality and the group: Advances in social identity (pp. 37-55). Sage Publications.

Radloff, L. S. (1977). The CES-D scale: A self-report depression scale for research in the general population. Applied Psychological Measurement, 1(3), 385-401.

Rutkowski, L., \& Svetina, D. (2014). Assessing the hypothesis of measurement invariance in the context of large-scale international surveys. Educational and Psychological Measurement, 74(1), 31-57.

Schimmack, U., Oishi, S., \& Diener, E. (2005). Individualism: A valid and important dimension of cultural differences between nations. Personality and Social Psychology Bulletin, 9(1), 17-31.

Schmitt, D. P., Realo, A., Voracek, M., \& Allik, J. (2008). Why can't a man be more like a woman? Sex differences in Big Five personality traits across 55 cultures. Journal of Personality and Social Psychology, 94(1), 168-182. https://doi.org/10.1037/a0014651

Schmitt, D. P. (2014). The evolution of culturally-variable sex differences: Men and women are not always different, but when they are. . it appears not to result from patriarchy or sex role socialization. In T. K. Shackelford \& R. D. Hansen (Eds.), The evolution of sexuality. Springer. https://doi.org/10.1007/9783-319-09384-0_11

Schwartz, S. H., \& Rubel-Lifschitz, T. (2009). Cross-national variations in the size of sex differences in values: Effects of gender equality. Journal of Personality and Social Psychology, 97(1), 171-185.

Schwartz, S. H., \& Rubel, T. (2005). Sex differences in value priorities: Cross-cultural and multimethod studies. Journal of Personality and Social Psychology, 89(6), 1010-1028. https://doi.org/10.1037/00223514.89.6.1010

Singelis, T. M. (1994). The measurement of independent and interdependent self-construals. Personality and Social Psychology Bulletin, 20(5), 580-591.

Smith, P. B. (2004). Acquiescent response bias as an aspect of cultural communication style. Journal of Cross-Cultural Psychology, 35(1), 50-61.

Smith, P. B., Fischer, R., Vignoles, V. L., \& Bond, M. H. (2013). Understanding social psychology across cultures: Engaging with others in a changing world. Sage.

Turner, J. C., Hogg, M. A., Oakes, P. J., Reicher, S., \& Wetherell, M. S. (1987). Rediscovering the social group: A self-categorization theory. Blackwell.

Van de Vijver, F. J. R., \& Leung, K. (1997). Methods and data analysis for cross-cultural research. Sage.

Vignoles, V. L., Owe, E., Becker, M., Smith, P. B., Easterbrook, M. J., Brown, R., González, R., Didier, N., Carrasco, D., Cadena, M. P., Lay, S., Schwartz, S. J., Des Rosiers, S. E., Villamar, J. A., Gavreliuc, A., Zinkeng, M., Kreuzbauer, R., Baguma, P., Martin, M., Tatarko, A., . . Bond, M. H. (2016). Beyond the 'East-West' dichotomy: Global variation in cultural models of selfhood. Journal of Experimental Psychology: General, 145(8), 966-1000.

Welzel, C. (2013). Freedom rising: Human empowerment and the quest for emancipation. Cambridge University Press.

Williams, J. E., \& Best, D. L. (1990). Sex and psyche: Gender and self viewed cross-culturally. Sage.

World Economic Forum. (2018). The global gender gap report 2018. http://reports.weforum.org/globalgender-gap-report-2018

Yuki, M. (2003). Intergroup comparison versus intragroup cooperation: A cross-cultural examination of social identity theory in North American and East Asian cultural contexts. Social Psychology Quarterly, 66(2), 166-183. 